\title{
Política pública: a televisão infantil na educação infantil
}

Valerio Fuenzalida

Professor e pesquisador na Faculdade de Comunicações da Pontifícia Universidade Católica do Chile.

E-mail: vfuenzal@uc.cl

Resumo: Desde meados da década de 1990 têm aparecido novos programas infantis de televisão que mostram novas representações do público infantil. A neurobiologia cerebral e as teorias epigenéticas do desenvolvimento infantil descobriram a imagem de uma criança com capacidades e motivações internas por desenvolver. Está se evoluindo para uma nova representação televisiva do público infantil e para um construtivismo cultural na recepção. Esses programas representam uma criança com competências socioemocionais. Essa representação infantil é mais complexa e convoca uma audiência construtivista dos programas. É necessário desenvolver uma política pública de introdução sistemática na educação infantil de tais programas de televisão com valor socioemocional de formação.

Palavras-chave: televisão infantil; educação; classe infantil; audiência construtivista; lar.
Abstract: Since the end of 1990 decade it has appeared new TV children productions with a new representation about children audience. Neurobiology and epigenetic theories on children development have presented an image of a child with internal competences and motivations to develop. There is an evolution towards this TV representation of child audience and towards a cultural constructivism in reception. Those TV programs represent child socioemotional intelligence; it is stated that the socio-emotional educational value of these TV programs vindicate a public policy for its systematic introduction in kinder class room. Programs require a constructivist reception at school and in family. Child constructivist reception allows a positive socio-emotional education.

Keywords: children television; education; children classroom; constructivist reception; home.

\section{NOVAS PRODUÇÕES TELEVISIVAS INFANTIS}

Desde a última década do século XX novos programas infantis de televisão têm surgido, em especial para crianças da pré-escola. Tais programas exibem uma "nova representação da criança e um novo desenho da realização televisiva"1. Segundo minha análise, essa nova imagem conceitual da criança e do bebê, que enfatiza a existência de complexas competências internas, começou a influir na produção dos programas infantis. Nota-se uma caracterização do

Recebido: 03/06/2016

Aprovado: 28/08/2016

1. FUENZALIDA, V. TV infantil: cambios en la narración y en escritura de guiones. [Televisão infantil: transformações na narração e na escrita de roteiros] Think Tank del Audiovisual - FCOM - PUC. www. accionaudiovisual.uc.cl, 2013. 
público infantil tomada das ciências contemporâneas. Alguns novos programas indicam o recurso à assessoria especializada de psicólogos e educadores. No presente artigo, serão apontadas algumas mudanças ocorridas na representação da criança e nos conteúdos dos programas.

\subsection{Imersão audiovisual do público}

Tem se tentado formas diversas de entrar em contato com esta criança-público tecnologicamente competente. Além da televisão, a criança atual vive em um ambiente cotidiano de crescente "imersão em múltiplataformas audiovisuais ubíquas: a tela do smartphone do computador, especialmente do tablet"2. Diante das múltiplas telas, a criança faz seleções, manipulações visuais e manuais, e conexões com outras crianças (intercâmbios, fã-clubes etc.). Alguns programas aludem à esta multiplataforma e criam sites e materiais para se relacionar com a criança que opera telas múltiplas (webpages, canais do YouTube, produtos comercializáveis). A imersão torna-se uma oferta infantil concebida em telas múltiplas. A imersão possibilita ainda uma exposição multimodal, na qual a multimodalidade tem um aspecto de significação semiótica específica, própria dos signos concretos, lúdicos e afetivos da linguagem audiovisual. A modalidade própria da linguagem audiovisual pode representar muito bem a diversidade concreta dos públicos, o protagonismo e as competências sócio-emocionais.

\section{Do espetáculo à interatividade}

Tem-se procurado representar no programa de televisão as capacidades e motivações internas da criança-público; do público considerado reativo aos estímulos da tela (modelo behaviorista) evoluiu-se para uma criança concebida como detentora de capacidade internas ativas, e capaz de se interessar em interpretar a proposta do programa. De um programa de televisão que era realizado com estímulos de percepção básicos para capturar a atenção da criança aparece uma ênfase na busca de interatividade com uma criança que tem outras capacidades internas de relação com o programa; isto é, que a criança não assista somente ao que está passando na tela, e, sim, que possa se relacionar interagindo com os conteúdos do programa e com outras telas.

2. VANDEWATER, E. A., RIDEOUT, V.; WARTELLA,

E. A.; HUANG, X.; LEE, J.H.; SHIM, M. Digital Childhood: Electronic Media and Technology Use among Infants, Toddlers, and Preschoolers. [Infância digital: uso de tecnologia e meios eletrônicos por crianças]. Pediatrics n. 119, 2007.
FIGURA 1 NOVA RELAÇÃO DE INTERAÇÃO CRIANÇA NO PROGRAMA E CRIANÇA-PÚBLICO

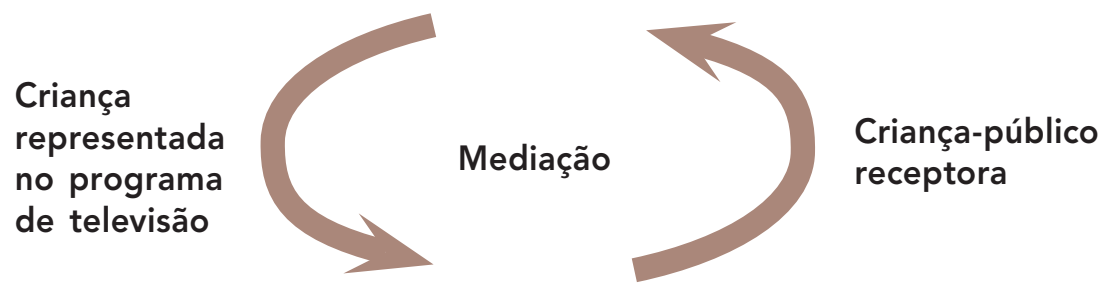


A Figura n. 1 ilustra a nova relação que o programa infantil pretende estabelecer com a criança-público. Para se estabelecer interação entre o público infantil e os conteúdos do programa de televisão, a produção criativa tem que representar a criança no programa. Ou seja, procura tornar visível a criança de modo que a criança-audiência possa reconhecer-se e identificar-se com a representada na tela. Rompe-se a relação unilateral da tela em direção à criança e busca-se uma relação circular de representação, visibilidade e interação. Entretanto, como se verá mais adiante, a polissemia da representação audiovisual oferece vários níveis de significação para o público infantil. Daí a necessidade da mediação construtivista pela audiência.

\section{Criança protagonista}

Trabalha-se o formato de relato com histórias lúdicas e não apenas o formato de módulos autônomos (formato inicial de Vila Sésamo; também presente agora na rede social hi5.com): $\mathbf{O}$ formato de história permite que a criança seja representada como protagonista da ação diegética, especialmente em histórias ficcionais. Da criança representada no programa como um aprendiz do adulto evolui-se para uma criança representada como protagonista dos programas; tende-se a abandonar o esquema criança - aprendiz do adulto oriundo da escola ${ }^{3}$.

\subsection{Segmentação das idades, conteúdos e formas}

As etapas etárias da evolução no desenvolvimento epigenético infantil vão influir na criação dos canais segmentados para crianças (nos anos 1990) e para a Baby TV (no século XXI), e também na presença de conteúdos e formas televisivas adequadas às capacidades de percepção, especialmente nos programas para crianças de 0 a 6 anos. Assim, as ciências do desenvolvimento infantil influenciarão na segmentação dos conteúdos, programas e canais. Antes, produzia-se televisão para crianças em geral, atualmente a televisão infantil tende a ser segmentada segundo o desenvolvimento das capacidades infantis. Há evidências de que à medida que a criança evolui, vai abandonando os programas de que gostava e prefere outros mais desafiadores a seu novo nível de desenvolvimento.

\subsection{A inteligência socioemocional}

Do ponto de vista dos conteúdos, por muitos anos pensou-se que uma televisão infantil de qualidade deveria exibir programas relacionados com os conteúdos escolares de linguagem e matemática; o programa Vila Sésamo foi concebido inicialmente como preparação para a escola, particularmente para crianças culturalmente vulneráveis. "A neurobiologia infantil revelou a importância da inteligência socioemocional, a atividade gestual-corporal, a
3. FUENZALIDA, V. Quality Criteria in children TV. [Critérios qualitativos na televisão infantil]. Amazon, 2015. 
4. MILICIC, N.; LÓPEZ DE LÉRIDA, S. La importancia del aprendizaje socioemocional en el contexto de la primera infancia. [A importância da aprendizagem sócio-emocional no contexto da primeira infância]. Estudios Sociales, n. 120, Santiago de Chile, CPU, 2012.

5. O desenvolvimento precoce das capacidade infantis socioemocionais fortalece as relações cidadãs; a neurobiologia reivindica a relação de empatia como base da cidadania e não apenas o pacto jurídico; do ponto de vista da filosofia, Nussbaum (2014) destaca a importância das emoções para o livre exercício da vida política.

6. LAVADOS, J. La neurobiología del aprendizaje temprano. [A neurobiologia da aprendizagem prematura]. Estudios Sociales, n. 120, Santiago: CPU, 2012.

7. WINNICOTT, D.W. Playing and Reality. [O brincar e a realidade]. Londres: Tavistock Publications, 1971. Realidad y Juego. Barcelona: Gedisa. 1992.

8. ANTINUCCI, F. ¿Colgados?. Qué hace la computadora con nuestros hijos, qué hacen nuestros hijos con la computadora. [Desligados? O que o computador faz com nossos filhos e o que nosso filhos fazem com o computador]. Buenos Aires: FCE, 2000.

9. HEINTZ, K. E.; WARTELLA, E. Young Children's Learning from Screen Media. [aprendizado na primeira infância através da tela da tevê]. Communication Research Trends, v. 31 n. 3, 2012. manipulação, a brincadeira, as emoções positivas, a auto-estima, as boas relações sociais e outras capacidades" ${ }^{\prime 45}$. Uma grande contribuição que se espera hoje da televisão para as crianças é a conexão com sua inteligência emocional; então aparece uma certa autonomia quanto aos conhecimentos escolares cognitivos e um interesse no desenvolvimento de outras capacidades das crianças. A nova imagem infantil significa que a criança não é apenas concebida a partir das competências mais tradicionais para aprender a língua materna, a leitura e a escrita e a matemática. A nova imagem coloca em questão que a criança tem capacidades socioemocionais importantíssimas para seu desenvolvimento presente e futuro, as quais deveriam ser consideradas por uma televisão atual de qualidade. Tem ainda capacidade lúdicas e imaginativas valiosas, que deveriam ser estimuladas, em vez de se desconfiar delas. Mas, além disso, é uma criança fisicamente muito ativa e que gosta de se exercitar. Portanto, uma televisão de qualidade deve estar conectada com essas novas capacidades internas conhecidas e valorizadas.

\subsection{Fruição e entretenimento}

De acordo com a neurociência ${ }^{6}$, as emoções positivas são índices de aprendizagem; valoriza-se, então, a fruição lúdica do agrado e do prazer que a criança sente diante de um programa de televisão; tal fruição emocional, compartilhada pela família e pelo professor, é a base de qualquer formação cognitiva que se pretenda obter adicionalmente ${ }^{7}$.

\subsection{0 videogame}

A área do videogame, em grande expansão, foi também incluída nas novas temáticas que são exploradas em seu potencial uso educativo, em distintos níveis escolares e extraescolares. O videogame produz um espaço de interação visual e manual no qual o usuário assume a tarefa de desafiar a si próprio. É operacional e interativo, sintetiza a habilidade, o prazer, a recompensa da vitória, a nova tentativa lúdica depois do fracasso $^{8}$. O videogame se apresenta também como um formato breve que desafia a criança, por exemplo, a encontrar letras, números e formas.

\section{RECEPÇÃO CONSTRUTIVISTA DA TELEVISÃO}

A pesquisa da recepção de programas infantis descobriu o chamado "vídeo déficit”, segundo o qual o público infantil de menos de 30 meses apresenta grandes dificuldades para descobrir a realidade pessoal e social apresentada em um programa de televisão". O "vídeo déficit" parecia confirmar a desconfiança formulada por Platão nas representações lúdico-simbólicas e acentuar o 
caráter enganoso da imagem visual, temor que reaparece periodicamente na cultura ocidental ${ }^{10}$. Hoje se interpreta o "vídeo déficit" como um programa inapropriado ao grau evolutivo de maturidade da criança, mas também como a insuficiência do programa de televisão isolado de um ambiente cultural construtivista na recepção.

Do ponto de vista da recepção dos programas de televisão, há evidências consistentes de que a televisão é compreendida e interpretada pelas crianças de acordo com sua adequação à maturidade evolutiva e em um ambiente interativo da classe e da família ${ }^{11}$; a utilidade da televisão para a formação não residiria em um programa isolado do ambiente sociocultural (como foi concebido pelo behaviorismo em meados do século XX).

A interpretação formativa desses programas não pode prescindir do processo de interação entre criança e adultos significativos ${ }^{12}$.

No campo da teoria, a hipótese é que a ficção produzida pela televisão é um "espaço lúdico de transição" quando é mediada pelo adulto, como pensava Winnicott sobre a interação lúdica e de fruição entre mãe e criança como transição para a cognição da realidade ${ }^{13}$. Na Espanha, Joan Ferrés ${ }^{14}$ também indicou que o olhar racionalista defensivo e pouco generoso com a televisão é contraditório com a experiência existencial de fruição no consumo de produtos televisivos em casa por parte do público, especialmente infantil e adolescente. Portanto, do ponto de vista da produção, a nova televisão infantil deveria ser projetada: a) para enfatizar a conexão com as competências internas da criança; b) para ser veiculada em um contexto cultural interativo (construtivista e de conexões) que ajude e estimule a criança. A utilidade de formação, então, não apenas se relaciona com a qualidade do programa, e sim com a qualidade das condições construtivistas da audiência.

Na verdade, os novos programas atualmente produzidos são necessários para garantir uma compreensão formativa por parte das crianças ${ }^{15}$. A interpretação do significado é complexa, pois existe a polissemia e também vários níveis de significação: dos níveis mais superficiais da história e da sequência narrativa até níveis mais profundos e implícitos como a representação de competências socioemocionais; a criatividade interpretativa do receptor infantil também deve ter um espaço de expressão. Surge a necessidade de criar uma situação cultural construtivista na recepção, interagindo com a interpretação pessoal da criança sobre o programa. Do ponto de vista teórico, abandona-se a concepção behaviorista de uma influência autônoma de um programa sobre um público individual e isolado do meio, e adere-se a uma concepção construtivista, na qual a expressão lúdica da criança e sua interação com o entorno sociocultural são necessárias para a compreensão interpretativa. A Figura 2 ilustra as mudanças da relação unilateral behaviorista para a relação construtivista com um receptor culturalmente contextualizado.
10. BESANÇON, A. La imagen prohibida: una historia intelectual de la iconoclasia.[A imagem proibida: uma história intelectual da iconoclastia]. Madri: Siruela, 2003.

11. HEINTZ; WARTELLA, op. cit.

12. FUENZALIDA, V. Cambios en la relación de los Niños con la Televisión. [Transformações na relação das crianças com a televisão]. Comunicar 30, n. XV, 2008.

13. WINNICOTT, op. cit.; SILVERSTONE, SILVERSTONE, R. Televisión y Vida Cotidiana. [Televisão e vida cotidiana] Buenos Aires: Amorrortu, 1996.

14. Cf. 2001, 2008 e 2014 nas Referências bibliográfica ao final do artigo.

15. NATHANSON, A.I.; SHARP, L.M.; ALADÉ, F.; RASMUSSEN, E.E.; CHRISTY, K. The Relation Between Television Exposure and Theory of Mind among Preschoolers [A relação entre a exposição à televisão e a teoria da mente entre os pré-escolares]. Journal of Communication, 63, n. 6, 2013. 
comunicação \& educação • Ano XXI • número 2 • jul/dez 2016

\author{
FIGURA 2 \\ CONCEPÇÃO BEHAVIORISTA E CONCEPÇÃO \\ CONSTRUTIVISTA DA RECEPÇÃO AUDIOVISUAL
}

\title{
Concepção behaviorista da recepção
}

TV

\section{INDIVÍDUO}

\section{Concepção construtivista da recepção}

16. A influência da televisão na obesidade infantil evoluiu da hipótese inicial de que a televisão diminuía a atividade física das crianças para a recente evidência de que o sobrepeso deveria ser atribuído ao grande consumo infantil de alimentos de baixa qualidade nutricional anunciados como desejáveis pela televisão; seria a exposição a propagandas persuasivas de alimentos pouco saudáveis e seu consumo o que explicaria a relação entre ver televisão e obesidade. A "epidemia da obesidade infantil" coloca em questão as dificudades dos pais em lidar com a forte capacidade de persuasão da publicidade (com apresentadores e astros do mundo infantil), e está levando à regulamentação da publicidade de televisão de alimentos dirigidos às crianças (SCHWARTZ; KUNKE; DELUCIA, 2013). Uribe e Fuentes-García (2013) acrescentam a necessidade de promover produtos alimentícios saudáveis e melhores estilos de vida para as crianças.

\section{TV}

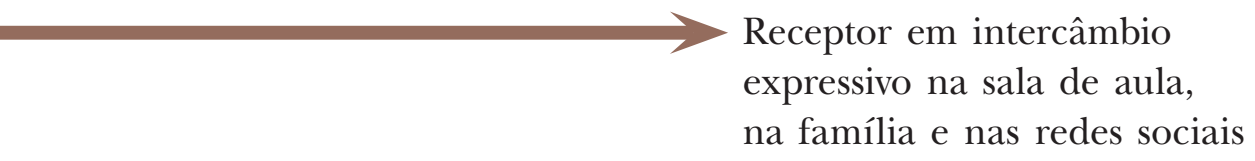

Com as transformações apontadas, necessita-se, segundo meu ponto de vista, de uma nova relação de formação entre a televisão infantil e a audiência: é a etapa da recepção construtivista na classe infantil. A finalidade de formação positiva seria a compreensão por parte da criança de suas próprias competências socioemocionais representadas de modo audiovisual pelo programa. Isso implica o desafio de produzir ambientes de fruição e construtivista de exibição/recepção para crianças. De um ponto de vista prático, tal construtivismo na recepção deveria ser proporcionado pela escola infantil e pela família. Mas também é necessário uma pesquisa etnográfica sobre os melhores ambientes e práticas construtivistas e as interpretações das crianças.

A recepção construtivista tem que levar em conta a diversidade da audiência infantil de televisão.

- Existem recentes programas da nova geração que buscam a conexão com as competências e energias socioemocionais da criança. A valorização interativa da fruição infantil com tais programas é a base da interpretação/apropriação construtivista.

- Existe também a publicidade televisiva que incita o consumo de comida pouco saudável, que provoca problemas de obesidade infantil. Diante desse tipo de conteúdo, a recepção deveria assumir um caráter desconstrutivista; são textos complexos e ambíguos, já que representam audiovisualmente produtos reais (trash food), com uma retórica persuasiva de atraente caráter lúdico ${ }^{16}$.

- Há uma considerável porcentagem diária de consumo infantil de programas de televisão cujos destinatários primários são jovens e adultos. Frequentemente tais programas mostram situações que os pais consideram inadequadas para as crianças; às vezes, as crianças não conseguem compreender os conteúdos ficcionais, ou se amedrontam diante dos conteúdos informativos. A mediação da família e da escola é necessária para a interpretação infantil de tais conteúdos. 


\section{TELEVISÃO INFANTIL PARA A CONTRIBUIÇÃO NA QUALIDADE DA EDUCAÇÃO INFANTIL}

A necessidade de introduzir de modo sistemático a recepção construtivista na educação infantil tem diversas razões.

\subsection{As crianças como as maiores consumidoras de televisão}

As crianças são grandes consumidoras de televisão: na atualidade, a televisão paga oferece na América Latina de dez a 12 canais infantis. A região tem uma média de cobertura de cerca de $50 \%$ de casas com televisão a cabo. Os dados do Ibope para a América Latina mostram que os canais infantis ocupam os quatro ou cinco primeiros lugares entre os dez mais assistidos da tevê a cabo. Na etapa final da infância, as crianças crescentemente transformam-se em "multitarefas" nas diversas plataformas disponíveis.

\subsection{Educação na tenra infância como base do desenvolvimento educacional posterior}

Dussaillant e González ${ }^{17}$ mostram que a educação infantil precoce aumenta a probabilidade de um melhor desempenho nos níveis escolares posteriores. $\mathrm{O}$ desenvolvimento da educação infantil em cobertura e qualidade demonstrou ser o investimento socialmente mais rentável do ponto de vista do momento cronológico mais efetivo no processo de educação total da população. Há, então, um fundamento de efetividade social para aproveitar a oportunidade de fortalecer a qualidade da educação infantil.

\subsection{Desenvolvimento da inteligência socioemocional}

Além disso, o conceito de qualidade na educação infantil ampliou-se para o desenvolvimento mais integral da criança, incluindo o aspecto que atualmente denomina-se inteligência socioemocional; esta inteligência refere-se à consciência de si mesmo e à consciência social, à autoimagem positiva de si mesmo, à responsabilidade na tomada de decisões, à resiliência e ao sentimento de capacidade, motivação interna ao desenvolvimento de suas capacidades, ao autocontrole e às relações sociais; mas o desenvolvimento de tais capacidades não foi tomado com o devido cuidado pela formação infantil, excessivamente centrada na preparação para as etapas escolares posteriores ("hiperescolarização”). No desenvolvimento infantil precoce dessas capacidades internas, hoje é considerado fundamental para a educação pessoal, social e cidadã, e para a escolarização posterior ${ }^{18}$.

A qualidade da educação infantil, especialmente no desenvolvimento da inteligência socioemocional integral da criança, atualmente pode ser decisivamente
17. DUSSAILLANT, F.; GONZÁLEZ, P. Rentabilidad de la inversión en primera infancia. [Rentabilidade do investimento na primeira infância]. Estudios Sociales, n. 120, 2012.

18. ILICIC; LÓPEZ DE LÉRIDA, op. cit. 
apoiada com os mencionados programas infantis de televisão da nova geração. É a oportunidade que aparece ao introduzir a nova televisão infantil no modo construtivista na aula infantil: incrementar a qualidade atual da educação infantil e tomá-la como base da aprendizagem posterior.

As mudanças mencionadas na nova produção de televisão infantil introduzem a necessidade da recepção construtivista na nova educação infantil. Com a recepção construtivista, a televisão deixa de ser concebida como uma ameaça à criança, que deveria dela ser protegida pela cultura social e familiar.

Assistir de modo construtivo, em sala de aula e em casa, a programas da nova geração pretendem ser um desafio de fruição das capacidades internas do público infantil com a criança competente representada na televisão.

\section{MODELO DE RECEPÇÃO CONSTRUTIVISTA}

A recepção construtivista propõe novos desafios à educação infantil.

\subsection{Construir um modelo de audiência construtivista para a aula}

Explorações em jardins da infância no Chile permitem recuperar a própria experiência das professoras ${ }^{19}$ que estão já usando programas infantis de modo espontâneo em sala de aula. A informação inicial permite propor uma estratégia de um modelo construtivista de recepção na sala de aula infantil.

Modelo sistemático. O modelo deve ser sistemático, programado sistematicamente com uma hora, uma vez por semana; deve procurar se relacionar com os conteúdos infantis.

Modelo flexível. Deve ser flexível para adaptar-se às diferentes crianças e em condições diversas (diferentes gostos, capacidade de atenção etc.).

Modelo construtivista. A sequência de atividades em uma hora poderia ser a seguinte:

- breve introdução com as crianças (assistem e se divertem com o programa em casa, por exemplo);

- exibição do programa selecionado;

- possíveis atividades construtivistas das crianças, as quais devem ser adequadas ao desenvolvimento:

- valorização, pelas professoras, da fruição expressiva e livre infantil e da interação com a tela;

- desenhar: expressão livre e pessoal sobre o programa; trabalhos com recortes e fotos, jogos de RPG, tirar fotos e gravar vídeos com smartphones e outras atividades;

- comentários em grupos de quatro crianças;

- comentários em grupo; 
- incentivar o intercâmbio entre crianças e pais, em casa, sobre o programa assistido.

\subsection{Avaliação e repetições}

É preciso trabalhar em experiências controladas e sua avaliação deve se dar tanto em relação aos resultados quanto ao aperfeiçoamento do modelo construtivista da audiência infantil. É preciso avaliar a estratégia adequada para as repetições de programas. As repetições são apreciadas pelas crianças e há evidências de que as repetições permitem às crianças o aprofundamento nas camadas de significados do programa. A hipótese é começar com três exibições do mesmo episódio de um programa:

Primeira exibição - centrada na fruição do episódio, compreensão da história com a respectiva tarefa ou desafio e ordenamento da sequência narrativa;

Segunda exibição - centrada nos personagens da ficção e em suas competências/capacidades;

Terceira exibição - centrada na identificação e reconhecimento: compreensão das competências/capacidades dos personagens da ficção; identificação com competências dos personagens da ficção e no reconhecimento das próprias competências das crianças. É a camada mais complexa e profunda.

Mas é preciso avaliar a estratégia adequada: repetições semanais ou intercaladas; quantidade de repetições produtivas para evitar o cansaço. Foco progressivo nas repetições.

\subsection{Capacitação de professoras}

Massificar a introdução da televisão infantil em sala de aula coloca em questão a capacitação das professoras de educação infantil em exercício, a formação sistemática e a formação sistemática das novas professoras de educação infantil.

\subsection{Capacitação de pais a partir da sala de aula infantil}

Pois não basta introduzir a televisão infantil na sala de aula infantil. Coloca-se o desafio de capacitar a família para uma ação construtivista com os filhos, especialmente com os menores. Sabe-se que a família realiza duas atividades básicas diante do ato de ver televisão dos filhos: a mediação deliberada e intencional diante da TV, e a modelagem; esta última não é deliberada, mas resultado das permanentes relações que a família sustenta na vida cotidiana com os programas de televisão, e na transmissão à criança das preferências e valores da cultura familiar diante da televisão. Se na família os pais não conversam com os filhos menores sobre os programas que assistem (e sobre os que não assistem), o silêncio dos pais cria um modelo com uma mensagem 
implícita: "o que você assiste na televisão não nos interessa porque não tem valor nem importância para nós". Assim, modela-se na criança um modo de assistir televisão como atividade não transcendente e irrelevante, mesmo que para a criança seja uma atividade interessante, prazerosa e potencialmente enriquecedora. É preciso, portanto, passar da modelagem passiva para uma mediação deliberada e construtivista.

Os pais atualmente quase não têm tempo de assistir televisão com os filhos, como frequentemente se recomenda. Para ajudar a família, tem-se criado folhetos com materiais para leitura, mas habitualmente são conselhos genéricos; os canais infantis a cabo criaram sites com sugestões para a família, mas parecem ser bem pouco consultados. Aparecem mensagens em emissoras de televisão chamando os pais a conversar com os filhos sobre a programação; mas eles não sabem com segurança o que comentar com os filhos.

A sala de aula infantil pode contribuir para capacitar os pais a familiarizar-se com alguns programas de televisão preferidos pelos filhos, apreciar os valores e atitudes neles representadas, e também para a realização de intercâmbios construtivistas (de acordo com a interpretação sociocultural) na recepção dos filhos. As avaliações nas escolas mostram que atividades ocasionais como "Semana da Família" ou "Semana da Televisão" têm baixa frequência. Propõe-se que as reuniões habituais de pais nas escolas dediquem permanentemente uns 15 minutos para destacar os programas valiosos e estimular os pais a comentar sobre eles com os filhos. É preciso então que as professoras de cada curso conheçam os programas favoritos dos seus alunos, comentem sobre eles com os pais e os estimulem a compartilhá-los com seus filhos; é um diálogo de interpretações e não de imposição de um significado fechado. Comentar interpretações de atitudes como as mencionadas anteriormente de protagonismo, autoconfiança, autoestima, capacidade de realizar, curiosidade, atividade, amizade, colaboração, tolerância, autoanálise e autocrítica, resiliência diante da adversidade e do fracasso, é uma forma de construtivismo que permite interagir explicitando interpretações e conteúdos de formação que a própria criança considera valiosos. A conversa é um sinal para a criança da importância atribuída pelos pais para a compreensão dos programas e seu valor de fruição.

Essa metodologia - de comentários construtivistas de professores aos pais no interior da escola a fim de ajudá-los a ser mediadores com seus filhos diante da televisão - considera o entretenimento e o prazer do ver televisão nas situações de descanso em casa. Mas pressupõe a capacitação para informar pais e professores sobre os programas exibidos e seus potenciais conteúdos de formação. Assim, pois, aparece aqui uma grande necessidade de capacitação e informação sobre os programas exibidos. 


\subsection{Formação de produtores e programadores de televisão infantil}

Os programadores de canais de televisão necessitam de capacitação para reconhecer os novos critérios de qualidade na televisão infantil. Da mesma forma, os profissionais especializados em elaboração e roteirização de programas infantis precisam conhecer os novos critérios de qualidade na produção televisiva infantil ${ }^{20}$. Além disso, é necessário explicitar os novos critérios de qualidade para a destinação de recursos públicos aos produtores interessados em produzir televisão infantil.

\subsection{Políticas públicas de exibição de televisão infantil na sala de aula infantil}

A introdução da televisão infantil na sala de aula infantil requer decisões políticas para os estabelecimentos públicos. Atualmente muitos municípios possuem canais públicos de televisão a cabo, o que facilita a chegada do conteúdo às salas de aula infantis. Muitos estabelecimentos já têm tecnologia para recepção de televisão aberta, por cabo, por satélite ou em streaming. Será necessário articular a transmissão dos canais com a recepção nas salas de aula infantis. Também aparece claramente a necessidade de um canal público infantil articulado com a sala de aula infantil, o que é possível de ser realizado com a atual tecnologia digital aberta.

\section{EM SÍNTESE}

A relação televisão e educação infantil evoluiu do objetivo de defesa diante da suposta vitimização produzida pelos programas contra as crianças para a reivindicação de uma televisão exibida e assistida construtivamente como desejável edu-entretenimento. Na primeira parte deste texto, indica-se que se está trabalhando na produção televisiva de "edu-entretenimento" para a formação específica em aspectos atitudinais-afetivos da inteligência emocional. É um novo campo de formação infantil, que contribui com a qualidade da educação em aspectos diferentes daqueles centrados em leitura e escrita. A revalorização do entretenimento lúdico permite a apreciação (e a produção) de textos edu-formativos, nas áreas afetivo-motivacionais. A formação afetivo-atitudinal foi revalorizada por uma antropologia evolutiva e pela neurobiologia cerebral mais sensíveis ao desenvolvimento da potencialidade social e emocional humanas. $\mathrm{Na}$ segunda parte do texto, indica-se que não basta a recepção televisiva em casa e que a sala de aula de educação infantil aparece como um valioso âmbito de trabalho. Argumenta-se que as novas produções não são interpretadas apenas em seu texto televisivo, mas que necessitam ser exibidas sistematicamente na sala de aula infantil, com uma recepção construtivista, para que o público infantil

20. FUENZALIDA, 2015, op. cit. 
interprete o valor positivo socioemocional. Propõem-se modelos de recepção construtivista para a sala de aula infantil. Em etapas etárias posteriores, os atuais meios, menores e de baixo custo, permitem aos professores e alunos a pesquisa e a expressão em temas de importância sociocultural para os estudantes; sua produção/recepção comentada permite uma reflexão construtivista com maior capacidade de incidência pragmática na vida cotidiana.

A centralidade da casa, entretanto, para a recepção da televisão pelas crianças - sob a égide do descanso e do prazer - leva a sustentar que não basta a formação sistemática da escola, mas, sim, que na sala de aula infantil deve-se capacitar a família para incentivar uma atitude interpretativa em casa. A capacitação das professoras e da família para a mediação construtivista traz novos desafios metodológicos em uma aliança entre pais e professores e a necessidade de novos instrumentos de formação.

A estratégia construtivista para assistir aos novos programas de televisão infantis na sala de aula infantil requer um canal público segmentado infantil, articulado com a sala de aula. E a articulação com o Ministério da Educação e as agências de educação infantil. Os componentes básicos desta estratégia são expostos sinteticamente na Figura 3.

FIGURA 3

COMPONENTES BÁSICOS DE UMA ESTRATÉGIA DE INTRODUÇÃO DA TELEVISÃO INFANTIL NA SALA DE AULA DE EDUCAÇÃO INFANTIL

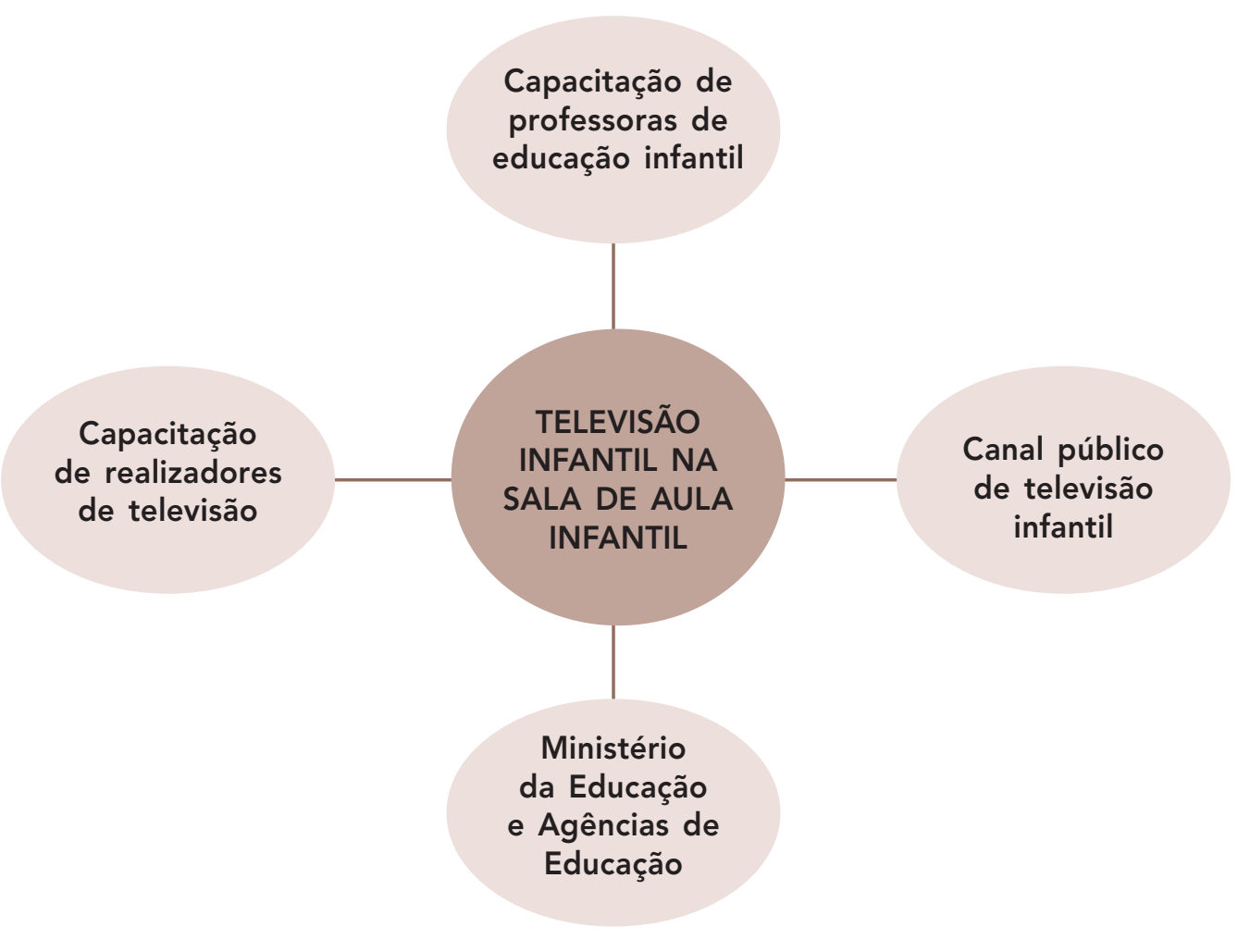




\section{ANEXO EPISTEMOLÓGICO: DA RECEPÇÃO PASSIVA À RECEPÇÃO CONSTRUTIVISTA}

\subsection{Da recepção crítica à recepção ativa}

É necessário recordar brevemente que durante as décadas iniciais da introdução da televisão, predominava a concepção de um público passivo diante da todo-poderosa influência televisiva. Tal concepção surgiu em um ambiente que considerou a televisão como ameaça cultural, moral e política; ela foi impulsionada por diversas teorias como o behaviorismo norte-americano e a Escola de Frankfurt, mas também por setores sociais religiosos que consideravam a televisão como fomentadora do consumismo e desestruturadora de valores morais ${ }^{21}$. Diante dessa ameaça, criou-se a concepção de um espectador crítico, o qual deveria desenvolver um consumo analítico-racional e consciente ante os perigos representados pela televisão. A fruição de um programa televisivo era considerada um agrado enganoso e prejudicial.

A evolução de um conceito de um espectador ativo foi influenciada por várias transformações na concepção tanto da televisão quanto da audiência. Uma primeira transformação foi situar a influência da televisão no interior da vida social e não de maneira isolada, como teorizava o behaviorismo. Uma segunda transformação foi a percepção, na década de 1970, que a unidade cultural da recepção da televisão (aberta ou paga) era a casa ${ }^{22}$; unidade atualmente repensada a partir da noção de recepção multiplataforma. Uma terceira transformação é uma nova compreensão positiva do conceito de entretenimento televisivo, enquanto espaço lúdico com potencial emancipador ${ }^{23}$. Uma quarta transformação é o conceito de expectativa educativa existencial, descoberto pela pesquisa etnográfica da recepção da televisão no interior da casa latino-americana, expectativa educativa-cultural, muito acentuada nas classes populares e médias. Uma quinta transformação é a desacoplagem que a recepção televisiva produz na antiga sinonímia entre educação televisiva e escola formal. Aparece no público uma expectativa de aprendizagem através da televisão, com duas diferenças em relação à escola: primeiramente, os conteúdos valorizados são aqueles relacionados às situações da existência e a problemas da vida cotidiana. Em segundo lugar, tal aprendizagem ocorre com frequência no interior da situação espaço-temporal de recepção-entretenimento, e pela via da identificação emocional com histórias corriqueiras de experiências pessoais mais do que por reflexão conceitual sobre leis gerais e abstratas (conhecimento científico ocidental).

O conjunto dessas mudanças levaram a uma nova conceituação da televisão, segundo a qual o meio deixa de ser considerado como agente onipotente e malvado, vitimizador de crianças indefesas e do público em geral. Na América Latina, tal transformação conceitual foi denominada, nos anos 1980 e 1990, como "recepção ativa", expressão preferida em relação à anterior "leitura ou recepção crítica”, pela conotação defensiva daquela formulação.
21. Posteriormente, foi se descobrindo que o espectador ativava suas capacidades de decodificação dos signos audiovisuais, mas os desconhecimentos daqueles anos não conseguiam reconhecer as competências culturais internas das crianças $e$, portanto, os programas de televisão não eram criados para se conectar a tais competências ativas dos públicos infantis.

22. FUENZALIDA, V. Televisión Abierta y Audiencia en América Latina. [Televisão aberta e audiência na América Latina]. Buenos Aires: Norma, 2002; Idem. Expectativas Educativas de las Audiencias Televisivas. [Expectativas educacionais nos espectadores de televisão]. Bogotá: Norma, 2005

23. FUENZALIDA, V. Reconceptualización de la Entretención ficcional televisiva. [Reconceitualização do entretenimento ficcional televisivo] Fronteiras. IX (1) 45-54. Porto Alegre: Universidad de Unisinos, 2007. 
24. MORDUCHOWITZ, R. Los chicos y las pantallas. [As crianças e as telas]. Fondo de Cultura Económica, 2014.

25. KANIZSA, G. Gramática de la visión. [Gramática da visão]. Buenos Aires: Paidós, 1986. KÖHLER, W. Psicología de la Forma. [Psicologia da forma]. Madri: Biblioteca Nueva, 1972.

26. DAMASIO, A. R. Sentir lo que sucede. Cuerpo y Emoción en la fábrica de la Consciencia. [Sentir o que acontece. Corpo e emoção na fábrica da consciência]. Santiago: Andrés Bello. (The Feeling of What Happens, 1998; 2001), p. 350; p. 40. Cf. JEANNEROD, M. Le cerveau et la représentation du monde sensible. [O cérebro e a representação do mundo sensível] In: OUDOT J., MORGON A., REVILLARD J.P. (eds.), Dix visions sur la communication humaine. [Dez visões sobre a comunicação humana] Lyon: Press Universitaires de Lyon, 1981.

27. VARELA, F.; THOMPSON, E.; ROSCH, E. De cuerpo presente. Sicología cognitiva. El perceptor/actor en el mundo. [De corpo presente. Psicologia cognitiva]. Barcelona: Gedisa, 1997.

28. VARELA, F.; PETITOT, J. Naturaliser la phenomenologie. [Naturalizar a fenomenologia]. Paris: CNRS, 2001.
Roxana Morduchowitz, especialista argentina em educação e comunicação, incorporou à recepção aspectos técnicos como a predominâncias de múltiplas telas e a capacitação em produção pessoal de mensagens. Ela sintetiza sua concepção da educação atual para a audiência da mídia em três aspectos complementares: acesso operacional à tecnologia; análise das mensagens; e produção de mensagens ${ }^{24}$.

\subsection{Percepção/Recepção construtivista}

Mas as atuais transformações na produção de televisão infantil, especialmente para a primeira infância e sua audiência apontam para o conceito de recepção construtivista.

O construtivismo na percepção humana tem um primeiro nível com bases estruturais sociobiológicas, estudadas primeiramente pela psicologia da percepção audiovisual, em especial pela psicologia alemã da Gestalt dos anos $1930^{25}$; tais estudos mostram que a percepção visual humana tem regras construtivistas próprias da espécie, bem diferentes das fórmulas matemáticas na "percepção" da lente audiovisual nas câmeras de cinema e fotográficas. O construtivismo foi confirmado pela neurobiologia cerebral: "O cérebro é um sistema criativo. Mais do que refletir o entorno, como faria um artefato mecânico, cada cérebro constrói mapas desse entorno [grifo nosso] usando seus próprios parâmetros e desenho internos, criando assim um mundo único para o tipo de cérebros planejados de tal maneira". ${ }^{26}$

Ao construcionismo bioestrutural na percepção humana é preciso acrescentar um segundo nível: o construcionismo semiótico-cultural. A semiótica demonstrou que a polissemia é um atributo destacado dos signos audiovisuais e base textual para a interpretação de diversos significados por parte dos espectadores; os estudos específicos de recepção televisiva demonstraram as diversas formas de interpretação dos programas, segundo o capital cultural e intertextual dos públicos (da mais elementar interpretação de aborrecer-se ou distrair-se com um programa). A partir da psicologia cognitiva, Francisco Varela acrescenta que o cérebro, mais do que um representador cognitivo da "realidade" é um preceptor-organizador da ação pragmática para a tarefa de viver no mundo ${ }^{27}$; a percepção tem um interesse construtivista pragmático para a sobrevivência do sujeito. Varela também constatou a existência de arquivos cerebrais onde fica armazenada a informação interna que interagirá com os dados provenientes da percepção externa; a percepção final é uma construção entre informação proveniente do exterior e informação interna $\operatorname{arquivada}^{28}$.

Contrariamente, o behaviorismo imperante durante grande parte do século XX concebia o ser humano em geral, e a criança em particular, como vazio internamente - tábula rasa - a concepção se originava em teorias filosóficas anteriores sobre o ser humano, mas tinha um importante apoio no 
desconhecimento do cérebro humano, pois não se dispunha de tecnologia para conhecer o cérebro humano internamente, operante e vivo. De acordo com o behaviorismo, aprender seria associar um estímulo externo ao sujeito com a resposta explicitada pelo sujeito aprendiz, e avaliada como correta pelo estimulador; as capacidades, as motivações e os processos programados internos da aprendizagem eram desconhecidos.

Com as técnicas da imagenologia, a neurobiologia cerebral foi descobrindo uma criança com competências internas, com capacidades e motivações surgidas de seu próprio interior; a aprendizagem infantil, segundo essa nova conceituação, é o desenvolvimento de tais capacidades e competências internas à criança ${ }^{29}$. Os estudos de psicologia evolutiva infantil indicam também uma potencialidade interna à criança como um desenvolvimento em etapas cronológicas, como aparecem em Freud, Piaget e na teoria epigenética de Erikson ${ }^{30}$. Também se destaca que para o adequado desenvolvimento dessas competências internas infantis é necessário que o entorno familiar e cultural conecte-se a elas estimulando essas capacidades programadas ${ }^{31}$.

A neurobiologia proporcionou um importante fundamento científico para a concepção do receptor ativo, já que tinha condições de demonstrar com a técnica da imagenologia as competências cerebrais internas no sujeito preceptor. A neurobiologia proporcionou uma nova conceitualização do espectador infantil, baseado na qual poderiam ser realizados programas de televisão conectados com as capacidades internas da criança. Mas também a neurobiologia e o desenvolvimento epigenético enfatizavam a necessidades de um ambiente sociocultural estimulante para o desenvolvimento apropriado de tais capacidades internas da criança; estas ciências destacavam o ambiente de recepção dos programas. Assim o construtivismo na audiência infantil aparece não somente como um fundamento etário particular, e sim como uma forma especial de participação na interpretação da televisão ${ }^{32}$.

Do ponto de vista epistemológico, produziu-se uma colisão do behaviorismo com a neurobiologia cerebral e com a psicologia cognitiva; talvez a mais conhecida controvérsia seja a afirmação de Chomsky ${ }^{33}$ sobre as competências inatas infantis para a aquisição da linguagem humana e sua sintaxe. Chomsky desqualificou os experimentos (com custos milionários) de ensinar linguagem humana a macacos, baseadas justamente na premissa da não necessidade de competências internas, já que a aprendizagem seria resultado do estímulo behaviorista externo ao animal. Aqui mencionam-se tais controvérsias para que se tenha consciência de um forte campo de conflitos e com enormes divergências. $O$ autor deste texto situa-se no campo do cognitivismo e da neurociência.
29. LAVADOS, J. La neurobiología del aprendizaje temprano. [A neurobiologia da aprendizagem prematura]. Estudios Sociales, n. 120, Santiago: CPU, 2012; Idem. El cerebro y la educación. Neurobiología del aprendizaje. [O cérebro e a educação. Neurobiologia da aprendizagem]. Santiago: Taurus, 2012(a).

30. PAPALIA, D. Desarrollo humano. [Desenvolvimento humano]. Nova York: McGraw-Hill, 2005.

31. CÉSPEDES, A. Cerebro, inteligencia y emoción: neurociencias aplicadas a la educación permanente [Cérebro, inteligência e emoção: neurociências aplicadas à educação continuada]. Santiago: Fundación Mírame, 2007.

32. LIVINGSTONE, S. The Participation Paradigm in Audience Research. [O paradigma da participação na pesquisa de audiência]. The Communication Review, 16, 2013.

28. VARELA, F.; PETITOT, J. Op. cit., 2001.

33. CHOMSKY, N. Reflections on Language. [Reflexões sobre a linguagem]. Nova York: Pantheon, 1975. 
comunicação \& educação • Ano XXI • número 2 • jul/dez 2016

\section{REFERÊNCIAS BIBLIOGRÁFICAS}

ANTINUCCI, F. ¿Colgados?. Qué hace la computadora con nuestros hijos, qué hacen nuestros hijos con la computadora. [Desligados? O que o computador faz com nossos filhos e o que nosso filhos fazem com o computador]. Buenos Aires: FCE, 2000.

BESANÇON, A. La imagen prohibida: una historia intelectual de la iconoclasia. [A imagem proibida: uma história intelectual da iconoclastia]. Madri: Siruela, 2003.

CÉSPEDES, A. Cerebro, inteligencia y emoción: neurociencias aplicadas a la educación permanente [Cérebro, inteligência e emoção: neurociências aplicadas à educação continuada]. Santiago: Fundación Mírame, 2007.

CHOMSKY, N. Reflections on Language. [Reflexões sobre a linguagem]. Nova York: Pantheon, 1975.

DAMASIO, A. R. Sentir lo que sucede. Cuerpo y Emoción en la fábrica de la Consciencia. [Sentir o que acontece. Corpo e emoção na fábrica da consciência]. Santiago: Andrés Bello. (The Feeling of What Happens, 1998; 2001).

DUSSAILLANT, F; GONZÁLEZ, P. Rentabilidad de la inversión en primera infancia. [Rentabilidade do investimento na primeira infância]. Estudios Sociales, n. 120, 2012.

FERRÉS I PRATS, J. Las pantallas y el cerebro emocional. [As telas e o cérebro emocional]. Barcelona: Gedisa, 2014.

La educación como industria del deseo. [A educação como indústria do desejo]. Barcelona: Gedisa, 2008.

Educar en una cultura del espectáculo. [Educar numa cultura do espetáculo]. Barcelona: Paidós, 2001.

FUENZALIDA, V. Televisión Abierta y Audiencia en América Latina. [Televisão aberta e audiência na América Latina]. Buenos Aires: Norma, 2002.

Expectativas Educativas de las Audiencias Televisivas. [Expectativas educacionais nos espectadores de televisão]. Bogotá: Norma, 2005.

Reconceptualización de la Entretención ficcional televisiva. [Reconceitualização do entretenimento ficcional televisivo]. Fronteiras. IX (1) 45-54. Porto Alegre: Universidad de Unisinos, 2007.

Cambios en la relación de los Niños con la Televisión. [Transformações na relação das crianças com a televisão]. Comunicar 30, n. XV, 2008.

- TV infantil: cambios en la narración y en escritura de guiones.

[Televisão infantil: transformações na narração e na escrita de roteiros] Think 
Tank del Audiovisual. FCOM-PUC. Disponível em: <www.accionaudiovisual. uc.cl>. Acesso em: 9 dez. 2016.

Quality Griteria in children TV. [Critérios qualitativos na televisão infantil]. Amazon, 2015.

HEINTZ, K. E.; WARTELLA, E. Young Children's Learning from Screen Media. [O aprendizado na primeira infância através da tela da tevê]. Communication Research Trends, v. 31, n. 3, 2012.

JEANNEROD, M. Le cerveau et la représentation du monde sensible. [O cérebro e a representação do mundo sensível]. In: OUDOT, J.; MORGON, A.; REVILLARD, J.P. (eds.), Dix visions sur la communication humaine. [Dez visões sobre a comunicação humana]. Lyon: Press Universitaires de Lyon, 1981.

KANIZSA, G. Gramática de la visión. [Gramática da visão]. Buenos Aires: Paidós, 1986.

KÖHLER, W. Psicología de la Forma. [Psicologia da forma]. Madri: Biblioteca Nueva, 1972.

LAVADOS, J. La neurobiología del aprendizaje temprano. [A neurobiologia da aprendizagem prematura]. Estudios Sociales, n. 120. Santiago: CPU, 2012.

. El cerebro y la educación. Neurobiología del aprendizaje. [O cérebro e a educação. Neurobiologia da aprendizagem]. Santiago: Taurus, 2012(a).

LIVINGSTONE, S. The Participation Paradigm in Audience Research. [O paradigma da participação na pesquisa de audiência]. The Communication Review, 16, 2013.

MILICIC, N.; LÓPEZ DE LÉRIDA, S. La importancia del aprendizaje socioemocional en el contexto de la primera infancia. [A importância da aprendizagem sócio-emocional no contexto da primeira infância]. Estudios Sociales, n. 120. Santiago de Chile, CPU, 2012.

MORDUCHOWITZ, R. Los chicos y las pantallas. [As crianças e as telas]. Fondo de Cultura Económica, 2014.

NATHANSON, A.I.; SHARP, L.M.; ALADÉ, F.; RASMUSSEN, E.E.; CHRISTY, K. The Relation Between Television Exposure and Theory of Mind among Preschoolers [A relação entre a exposição à televisão e a teoria da mente entre os pré-escolares]. Journal of Communication, 63, n. 6, 2013.

NUSSBAUM M. Emociones Políticas. [Emoções políticas]. Buenos Aires: Paidós, 2014.

PAPALIA, D. Desarrollo humano. [Desenvolvimento humano]. Nova York: McGraw-Hill, 2005. 
SILVERSTONE, R. Televisión y vida cotidiana. [Televisão e vida cotidiana]. Buenos Aires: Amorrortu, 1996.

SCHWARTZ, M.; KUNKEL, D.; DELUCIA, S. Food Marketing to Youth: Pervasive, Powerful, and Pernicious. [Publicidade de alimentos para jovens: penetrante, poderosa e perniciosa]. Communication Research Trends, 32, 2, 2013 .

URIBE, R.; FUENTES-GARCÍA, A. Food Marketing, Children, and Obesity in Chile: Evidence and Challenges for Regulation.[Publicidade de alimentos, infância e obesidade no Chile: evidências e desafios para a regulação]. Communication Research Trends, 32, 2, 2013.

VANDEWATER, E. A.; RIDEOUT, V.; WARTELLA, E. A.; HUANG, X.; LEE, J.H.; SHIM, M. Digital Childhood: Electronic Media and Technology Use among Infants, Toddlers, and Preschoolers. [Infância digital: uso de tecnologia e meios eletrônicos por crianças]. Pediatrics, n. 119, 2007.

VARELA, F.; THOMPSON, E.; ROSCH, E. De cuerpo presente. Sicología cognitiva. El perceptor/actor en el mundo. [De corpo presente. Psicologia cognitiva]. Barcelona: Gedisa, 1997.

; PETITOT, J. Naturaliser la phenomenologie. [Naturalizar a fenomenologia]. Paris: CNRS, 2001.

WINNICOTT, D.W. Playing and Reality. [O brincar e a realidade]. Londres: Tavistock Publications, 1971. Realidad y Juego. Barcelona: Gedisa, 1992. 